\title{
Yield, chemical composition and antibacterial activity of Ruta chalepensis L. essential oil growing spontaneously in Algeria
}

\begin{abstract}
As part of the development of Algerian natural products, mainly of plant origin, we are interested in the study of the essential oil of Ruta chalepensis L. collected from Souk ahras (North-east of Algeria) obtained by hydro-distillation. Characterization of these species was made by determining yield and chemical composition. The essential oil yield of the dried plant obtained was $0.65 \%(\mathrm{v} / \mathrm{w})$. The identification of the chemical composition of the essential oil from aerial parts was carried out thanks to gas chromatography analysis coupled to mass spectrometry (GC/MS). Twenty compounds, representing for $97.25 \%$ of the essential oil, were identified. The major constituents were 2-Dodecanone (40.15\%), 2-Nonanone (24.20\%) and 1-Nonene (15.10\%). Antimicrobial activity was tested against four pathogenic bacteria; Staphylococcus aureus (ATCC 29737), Bacillus subtilis (MTCC 5981), Escherichia coli (ATCC 25922) and Pseudomonas aeruginosa (ATCC 33988). The obtained results indicate possible applications for Ruta chalepensis L. in the treatment of various infectious and noninfectious diseases.
\end{abstract}

Keywords: Ruta chalepensis L., essential oil, yield, chemical composition, antibacterial activity
Volume 7 Issue I - 2019

\author{
Hicham Boughendjioua \\ Department of Natural Sciences, High School Professors \\ Technological Education, Algeria
}

Correspondence: Hicham Boughendjioua, Department of Natural Sciences, High School Professors Technological Education, Skikda, 21000, Algeria, Tel +213(0)699259337, Email boughendjioua.hicham@yahoo.com

Received: January 29, 2019 | Published: February 22, 2019

\section{Introduction}

A large number of aromatic plants and medicinal has biological properties very interesting who find applications in various fields such as the pharmaceutical industries, the medicine, cosmetic industries and agribusiness. These plants represent a new source of active compounds. Indeed, the metabolites secondary are the subject of numerous in vivo and in vitro research, including search for new natural constituents such as phenolic compounds, saponins and essential oils. The evaluation of their biological properties as antioxidants and antimicrobial remains a very interesting and very useful spot. ${ }^{1}$

Ruta chalepensis, is a species of flowering plant of the family Rutaceae. Native to Eurasia and North Africa, this perennial medicinal plant is a species widely introduced elsewhere. ${ }^{2}$ The species is hairless, not glandular at the top, $30-80 \mathrm{~cm}$, and its broad leaves (from which the synonym Ruta macrophylla, "Broad-leaved street") are composed (the stipule-like and petiolate lower ones), each divided into several parts. segments that are subdivided into smaller oval-oblong leaflets (hence its synonym for Ruta angustifolia, "narrow-leafed street"). ${ }^{3}$ The inflorescence is a raceme of racemes of flowers composed of four or five bright yellow petals with laminated fringed edges. The fruiting bunch, more corymb form and less loose, gives as fruit parchment capsules which are divided into pointed lobes. Seed spread is barochorous. ${ }^{4}$ This medicinal plant is still used for its antispasmodic, circulatory tonic, anti-inflammatory, antibiotic and insect repellent properties. ${ }^{5}$ There are four Ruta species and subspecies in Algeria, Ruta montana, Ruta chalepensis subsp. angustifolia, Ruta chalepensis subsp. latifolia and the Saharian species Ruta tubercula. ${ }^{6}$

Plants produce a wide diversity of secondary metabolites (SM) which serve them as defense compounds against herbivores, and other plants and microbes, but also as signal compounds. In general, SM exhibit a wide array of biological and pharmacological properties. Because of this, some plants or products isolated from them have been and are still used to treat infections, health disorders or diseases.
This review provides evidence that many SM have a broad spectrum of bioactivities. They often interact with the main targets in cells, such as proteins, biomembranes or nucleic acids. Whereas some SM appear to have been optimized on a few molecular targets, such as alkaloids on receptors of neurotransmitters, others (such as phenolics and terpenoids) are less specific and attack a multitude of proteins by building hydrogen, hydrophobic and ionic bonds, thus modulating their 3D structures and in consequence their bioactivities. The main modes of action are described for the major groups of common plant secondary metabolites. The multitarget activities of many SM can explain the medical application of complex extracts from medicinal plants for more health disorders which involve several targets. Herbal medicine is not a placebo medicine but a rational medicine, and for several of them clinical trials has shown efficacy. ${ }^{7}$

In order to contribute to the valorization of Algerian flora with a view to identifying new potentially interesting substances at the biological and therapeutic levels, we proceeded to the study in vitro effect of essential oil of Ruta chalepensis L. on a set of pathogenic bacteria.

\section{Plant material}

Ruta chalepensis L. leaves were collected from Souk ahras (Northeast of Algeria) where it grows spontaneously. were collected on May 2017. The taxonomic identity of the plant was confirmed by the wellknown Algerian flora of Quezel and Santa. ${ }^{8}$

\section{Essential oil extraction}

Essential oil was extracted from fresh leaves (300 g) by hydrodistillation using a Clevenger apparatus for $03 \mathrm{~h}$. The isolated essential oil was dried over anhydrous sodium sulphate and stored at $4-6^{\circ} \mathrm{C}$ until tested and analyzed. The percentage yield of essential oil was calculated on the weight basis. The equation is as follows: Volatile oil $(\%)=($ Weight of the volatile essential oil recovered in $\mathrm{g} \times 100) /$ Weight of sample taken in $\mathrm{g}$. 


\section{Analysis of the essential oil}

The GC-MS analysis was performed using a Hewlett Packard 5973-6800 system operating in EI mode $(70 \mathrm{eV})$ equipped with a split/splitless injector $\left(250^{\circ} \mathrm{C}\right)$, a split ratio $1 / 50$, using a fused silica HP-5 MS capillary column $(30 \mathrm{~m} \times 0.25 \mathrm{~mm}$ (i.d.), film thickness: $0.25 \mu \mathrm{m}$. The temperature program for the HP-5 MS column was from $60^{\circ} \mathrm{C}$ to $280^{\circ} \mathrm{C}$ at a rate of $2^{\circ} \mathrm{C} / \mathrm{min}$. Helium was used as a carrier gas at a flow rate of $0.5 \mathrm{ml} / \mathrm{min}$. Injection volume of the sample was $0.2 \mu$ l. The identification of the components was conducted in an IS system managing a library of spectrum wiley 7 n.1.

\section{Antibacterial activity}

The antibacterial activity of the essential oil was assessed by the agar disk diffusion assay, against four human pathogenic bacteria, two strains of gram-positive bacteria; Staphylococcus aureus (ATCC 29737) and Bacillus subtilis (MTCC 5981) and two strains of gramnegative bacteria; Escherichia coli (ATCC 25922) and Pseudomonas aeruginosa (ATCC 33988). Microorganisms were obtained from the bacteriology laboratory, Dorban university hospital center, Annaba (Algeria).

\section{Results and discussion}

\section{Yield and chemical analysis of the essential oil}

The yields of Ruta chalepensis L. essential oil was significantly $(\mathrm{p}<0.05)$, the amount obtained from the dried plant was $0.65 \%(\mathrm{v} / \mathrm{w})$. This performance is comparable to that obtained for the same wildlife species studied in the region of Tlemcen (Algeria) whose yield was $0.31 \%$ for the rods, $0.69 \%$ for the leaves and $1.22 \%$ for the flowers (Table 1). ${ }^{9}$

Table I Ruta chalepensis L. essential oil yields depending on the harvest period

\begin{tabular}{llllll}
\hline $\begin{array}{l}\text { The harvest } \\
\text { period }\end{array}$ & February & April & June & August & October \\
\hline The yield (\%) & 0.28 & 0.84 & 0.78 & 0.72 & 0.43
\end{tabular}

In contrast, this performance was revealed different than that given by the same species from different regions in Lebanon, ${ }^{10}$ Tunisia, ${ }^{11}$ Iran $^{12}$ and Morocco ${ }^{13}$ whose performance can reach $0.12 \%, 0.34$ $\%, 0.4 \%$ to $0.56 \%$. This difference can be attributed to several factors such as climate and geographical conditions and the period of harvesting and drying conditions. It has been shown that drying affects the performance of essential oil: a plant dried in non-optimal condition may lose all of its essential oil. GC/MS chromatogram for typical Ruta chalepensis L. essential oil analyzed presently is shown in Table 2.

The chromatographic analyses resulted in the identification of 20 compounds, representing 2-Dodecanone (40.15\%), 2-Nonanone $(24.20 \%)$ and 1 -Nonene $(15.10 \%)$ were the major components. Literature survey on the chemical constituents of Ruta chalepensis L. essential oil revealed a great variability, which may have been due to several factors, among the geographical location, season and environmental factors, as well as the part of the plant used and extraction method. These results were not in agreement with previous research reported for the same plant. The chemical constituents of the essential oil of Ruta graveolens L. from aerial parts collected from Iran were analyzed by GC and GC/MS. Nineteen compounds, representing for $95.2 \%$ of the oil, were identified. The main classes of compounds were found to be ketons $(46.6 \%)$ and sesquiterpenoids $(13.3 \%)$ and monoterpenoids $(4.1 \%)$. The major constituents were 2-undecanone (33.9\%), 2-Heptanol acetate (17.5\%), 1-dodecanol $(11.0 \%)$, geyrene $(10.4 \%)$ and 2-nonanone $(8.8 \%) .^{12}$

Table 2 Chemical composition of Ruta chalepensis L. essential oil

\begin{tabular}{llll}
\hline $\mathbf{N}^{\circ}$ & Compound & Retention time (min) & Peak area (\%) \\
\hline 1 & $\alpha$ - Pinene & 6.3 & 0.9 \\
2 & Camphene & 6.75 & 0.45 \\
3 & 3-Pinene & 7.39 & 0.55 \\
4 & 2-Octanone & 7.65 & 0.59 \\
5 & Limonene & 8.48 & 0.29 \\
6 & 1,8-Cineole & 8.6 & 1.65 \\
7 & G-Terpinene & 9.2 & 0.99 \\
8 & 2-Nonanone & 10.2 & $\mathbf{2 4 . 2}$ \\
9 & 2-Nonanol & 10.31 & 1.7 \\
10 & Nonanal & 10.4 & 0.8 \\
11 & Geyrene & 11.1 & 1.36 \\
12 & Camphor & 11.15 & 0.98 \\
13 & Borneol & 11.64 & 0.78 \\
14 & 2-Decanone & 12 & 2.5 \\
15 & Octyl acetate & 12.44 & 0.97 \\
16 & 1-Nonene & 13.11 & $\mathbf{1 5 . 1}$ \\
17 & 2-Undecanone & 13.37 & 0.87 \\
18 & 2-Dodecanone & 14.19 & $\mathbf{4 0 . 1 5}$ \\
19 & 2-Tridecanone & 17.8 & 0.92 \\
20 & Viridiflorol & 21.59 & 1.5 \\
\hline & 2- &
\end{tabular}

On the other hand, in Iran also, water-distilled essential oil from aerial parts of Ruta chalepensis L. was analyzed by GC and GC/MS. Eleven compounds representing $92.9 \%$ of the oil were identified. 2-Undecanone (52.5\%) and 2-nonanone (24.1\%) were the major constituents. ${ }^{14}$ In Tunisia (Jemmel, Monastir), the chemical composition of essential oils extracted from different fresh parts of Ruta chalepensis: flowers, leaves and stems, was analyzed using GC and GC/MS. Fifty-three components were identified in the oil of each organ. Ketones occurred as the major constituent of the three organs volatile oils while nonan-2-one was the most notably dominating compound in stems essential oil and undecan-2-one was the major compound in flowers and leaves essential oils. ${ }^{15}$ The determination of chemical composition analyzed by GC/FID and GC/MS of essential oil obtained by hydro-distillation of Leaves of Ruta chalepensis L. collected from the region of Tensift Al Haouz (High Atlas Mountains) Marrakech, Morocco gave twenty-two compounds were identified and accounted for $92.4 \%$ of the total oil composition. The major components were undecan-2-one (49.08\%), nonan-2-one (33.15\%), limonene $(4.19 \%)$ and decanone $(2.71 \%){ }^{13}$

The essential oil of the aerial parts of Ruta chalepensis L. from Greece were investigated by GC/MS. Forty-four components were identified in the oil, representing $95.1 \%$. The main components were beta-phellandrene $(10.7 \%)$ and 2-methyloctyl acetate $(44.0 \%) .^{16}$ Steam distilled essential oil from aerial parts of Ruta chalepensis growing in Turkey was analyzed by GC and GC/MS. Twentyfour compounds were identified representing $93.4 \%$ of the oil with 2-undecanone $(66.49 \%)$ and 2-nonanone $(16.24 \%)$ as major constituents. ${ }^{17}$ The phytochemical profile of the Ruta chalepensis essential oil components from Hebron region was almost similar to 
Jerusalem region and the total components of the essential oil were $96.75 \%$ and $96.3 \%$, respectively. In addition, they contained major phytochemical classes such as alcohol which represented 32.36 $\%$ and $38.24 \%$, respectively, ketone group $31.16 \%$ and $18.27 \%$, respectively; and ester group which represented $29.51 \%$ and 35.05 $\%$, respectively. ${ }^{18}$

The essential oil obtained by hydro-distillation of aerial parts of Ruta chalepensis subsp. angustifolia from Algeria was analyzed by GC and GC/MS. 16 compounds were characterized representing $99.99 \%$ of the essential oil with 2-acetoxytetradecane (58.44\%), 2-acetoxytridecane $(19.07 \%)$ and 2-tridecanone $(6.39 \%)$ as major components. ${ }^{6}$ This deviation from the common chemo-types may be attributed to the effect of the factors that specifically affect the composition and yield of the essential oil, which include seasonal and maturity variation, geographical origin, genetic variation, growth stages, postharvest drying and storage. ${ }^{19-23}$

\section{Antimicrobial activity}

Ruta chalepensis L. essential oil presented a moderate inhibition activity against all the bacterial strains tested (Table 3).

Table 3 Anti-microbiological activity of Ruta chalepensis L. essential oil

\begin{tabular}{ll}
\hline Strains & Sensitivity* \\
\hline Staphylococcus aureus (ATCC 29737) & ++ \\
Bacillus subtilis (MTCC 5981) & ++ \\
Escherichia coli (ATCC 25922) & ++ \\
Pseudomonas aeruginosa (ATCC 33988) & ++
\end{tabular}

Each value represents the mean of two replicates \pm standard deviation

*The sensitivity to the different strains was classified by the diameter of the inhibition zone as follows: 23

-: diameter less than $8 \mathrm{~mm}$, not sensitive;

+: sensitive, diameter $9-14 \mathrm{~mm}$;

++ : very sensitive, diameter $15-19 \mathrm{~mm}$;

+++ : extremely sensitive for diameter larger than $20 \mathrm{~mm}$.

The activity of the essential oils would be expected to relate to the chemical composition and their functional groups and possible synergistic interactions between components. ${ }^{24}$ The antibacterial activity of Ruta chalepensis subsp. angustifolia essential oil from Algeria was tested against a range of microorganisms, namely; Escherichia coli (ATCC 25922), Escherichia coli (HS), Staphylococcus aureus (ATCC 2913), Staphylococcus aureus (HS), Pseudomanas aeruginosa (ATCC 27853), Pseudomonas aeruginosa (HS), Klebsiella pneumoniae (ATCC), Klebsiella pneumonia (HS) and Streptococcus enterococcus (HS). The essential oil inhibited remarkably the growth of Klebsiella pneumoniae (ATCC), Klebsiella pneumoniae (HS), Escherichia coli (ATCC), Escherichia coli (HS), Streptococcus enterococcus (HS) and Pseudomonas aeruginosa (ATCC) strains with 21, 21, 20, 20, 20 and $20 \mathrm{~mm}$ (inhibition zone diameters, respectively. ${ }^{6}$

The essential oil of Ruta chalepensis from Jerusalem, Hebron and Jenin regions of Palestine extracted by microwave-ultrasonic method exhibited interesting potential bioactivity against the growth of all microbes examined; Staphylococcus aureus (ATCC 25923), Escherichia coli (ATCC 25922) and Pseudomonas aeruginosa (ATCC 27853) as well as against the growth of a diagnostically confirmed clinical isolates Methicillin Resistant Staphylococcus aureus (MRSA). The highest antibacterial activity (lowest MIC) against bacterial pathogen examined was for Ruta chalepensis essential oil and was seen against Staphylococcus aureus, Escherichia coli, Pseudomonas aeruginosa and Methicillin Resistant Staphylococcus aureus with MIC values of $0.75 \mathrm{mg} / \mathrm{ml}, 7 \mathrm{mg} / \mathrm{ml}, 2.5 \mathrm{mg} / \mathrm{ml}$, and $4 \mathrm{mg} /$ $\mathrm{ml}$, respectively, in comparison with gentamycin which has MIC values of $0.5 \mathrm{mg} / \mathrm{ml}, 2 \mathrm{mg} / \mathrm{ml}, 0.5 \mathrm{mg} / \mathrm{ml}$, and $1.5 \mathrm{mg} / \mathrm{ml}$, respectively. ${ }^{18}$

Ben Bnina ${ }^{15}$ report that Escherichia coli (ATCC 35218), Salmonella thyphimirium (LT2), Pseudomonas aeruginosa (ATCC 27853) were resistant against essential oil of Ruta chalepensis. This result agrees to the nature of this strain recognized as multiresistant against many antibiotics and biocides agents. The results obtained show that the essential oil of Ruta montana from the region of Tablat, Médéa (Algeria) has a more or less moderate activity for; Staphylococcus aureus (ATCC 6538), Bacillus subtilis (ATCC 9372) and Candida albicans (ATCC 24433), except in the case of Klebsiella pneumoniae (ATCC 4352), where the growth of the latter is strongly inhibited, with a diameter of the zones of inhibition $59.7 \mathrm{~mm}$. On the other hand, Pseudomonas aeruginosa (ATCC 9027) has practically no sensitivity with respect to this oil, with a diameter of the inhibition zones of 10 $\mathrm{mm}$, knowing that the disks have a diameter of $9 \mathrm{~mm} .{ }^{25}$

\section{Conclusion}

This study aims to contribute to the knowledge of essential oil of Ruta chalepensis L., a spontaneous species, very abundant in Algeria, products that generally pose serious problems of standardization for their commercialization, because of the diversity of their composition, recognized by all scientists and users. This work also allowed determining the yield and the chemical composition of the essential oil and to identify are chemotype. It appears that 2-undecanone is the chemotype of most essential oils of Ruta species, we can conclude that it's a marker of this plant. In addition, the composition of the essential oil of Ruta chalepensis L. from Souk ahras (North-east of Algeria) obtained by hydro-distillation was different; it contained 2-Dodecanone (40.15\%), 2-Nonanone $(24.20 \%)$ and 1-Nonene $(15.10 \%)$. Finally, the results of this work, can be exploited for use by the aromatic plants industry. Antibacterial assays, showed that the essential oil was active against; Staphylococcus aureus, Bacillus subtilis, Escherichia coli and Pseudomonas aeruginosa. We can indeed direct the production and the exploitation of the essential oil of Ruta chalepensis L. according to the needs of the users in definite products that are supposed to exist in large proportions.

\section{Acknowledgments}

None.

\section{Conflicts of interest}

Author declares that there is no conflicts of interest.

\section{References}

1. Slimani A, Moussaoui A, Laazouni H. Phytochemical screening, contribution to the study of the antifungal effect of flavonoids from different parts of Ziziphus lotus of south-west Algeria. Asian Journal of Pharmaceutical and Clinical Research. 2017;10(2):13-16.

2. Arnason JT, Mata R, Romeo JT. Phytochemistry of Medicinal Plants. New York: Springer Science \& Business Media; 1995. 72 p.

3. Couplan F. Plants and their names: Unusual stories. Editions Quae; 2012. 156 p. 
4. Ruta chalepensis. eFlore: Tela Botanica.

5. Al-Said MS, Tariq M, Al-Yahya MA, et al. Studies on Ruta chalepensis, an ancient medicinal herb still used in traditional medicine. Journal of Ethnopharmacology. 1990;28(3):|305-312.

6. Chibani S, Bouratoua A, Kabouche A, et al. Composition and antibacterial activity of the essential oil of Ruta chalepensis subsp. Angustifolia from Algeria. Der Pharmacia Lettre. 2013;5(5):252-255.

7. Wink M. Modes of Action of Herbal Medicines and Plant Secondary Metabolites. Medicines. 2015;2(3):251-286

8. Quezel P, Santa S. New flora of Algeria and southern desert regions. Paris: Éditions du centre national de la recherche scientifique; 1962. 793 p.

9. Merghache S, Hamza M, Tabti B. Etude physicochimique de l'huile essentielle de Ruta Chalepensis L. de Tlemcen, Algérie. Afrique Science. 2009;5(1):67-81.

10. Khoury M, Stien D, Ouaini N, et al. Chemical Composition and Antimicrobial Activity of the Essential Oil of Ruta chalepensis L. Growing Wild in Lebanon. Chemistry \& Biodiversity. 2014;11(12):1990-1997.

11. Majdoub O, Dhen N, Souguir S. Chemical Composition of Ruta chalepensis Essential Oils and their Insecticidal Activity against Tribolium castaneum. Tunisian Journal of Plant Protection. 2014;9(1):83-90

12. Soleimani M, Azar PA, Tehrani MS, et al. Volatile Composition of Ruta graveolens L. of North of Iran. World Applied Sciences Journal. 2009;7(1):124-126.

13. Bouajaj S, Romane A, Benyamna A, et al. Essential oil composition, phytotoxic and antifungal activities of Ruta chalepensis L. leaves from High Atlas Mountains (Morocco). Natural Product Research. 2014;28(21):1910-1914.

14. Rustaiyan A, Khossravi M, Sultani-Lotfabadi F, et al. Constituents of the essential oil of Ruta chalepensis L. from Iran. Journal of Essential Oil Research. 2002;14(5):378-379.
15. Ben Bnina E, Hammami S, Daamii-remadi $M$, et al. Chemical composition and antimicrobial effects of tunisian Ruta chalepensis $\mathrm{L}$. essential oils. Journal de la Société Chimique de Tunisie. 2010;12(1):1-9.

16. Tzakou O, Couladis M. Essential oil of Ruta chalepensis L. from Greece. Journal of Essential Oil Research. 2001;13(4):258-259.

17. Baser KHC, Özek T, Beis SH. Constituents of the essential oil of Ruta chalepensis L. from Turkey. Journal of Essential Oil Research. 1996;(8)4:413-414.

18. Jaradat N, Adwan L, Kaibni S, et al. Variability of Chemical Compositions and Antimicrobial and Antioxidant Activities of Ruta chalepensis Leaf Essential Oils from Three Palestinian Regions. BioMed Research International. 2017;2672689:1-9.

19. Marotti M, Piccaglia R, Giovanelli E. Effects of variety and ontogenic stage on the essential oil composition and biological activity of fennel (Foeniculum vulgare Mill.). Journal of Essential Oil Research. 1994;6(1):57-62.

20. Hussain AI, Anwar F, Sherazi ST, et al. Chemical composition, Antioxidant and antimicrobial activities of basil (Ocimum basilicum) essential oils depends on seasonal variations. Food Chemistry. 2008;108(3):986-995.

21. Butkiene R, Sakociute V, Latvenaite D, et al. Composition of young and aged shoot essential oils of the wild Ledum palustre (L.). Chemija. 2008;19(2):19-24.

22. Verma RS, Verma RK, Chauhan A, et al. Changes in the essential oil content and composition of Eucalyptus citriodora Hook during leaf ontogeny and leaf storage. Indian Perfumer. 2009;53:22-25.

23. Ponce AG, Fritz R, Del Valle C, et al. Antimicrobial Activity of Essential Oils on the Native Microflora of Organic Swiss Chard. LWTFood Science and Technology. 2003;36(7):679-684.

24. Dobre AA, Niculiţă P. Antibacterial Profile of Essential Oils against Pathogen Bacteria. Bulletin UASVM Agriculture. 2012;69(2): 255-261.

25. Hazzit M, Benchabane A, Baaliouamer A, et al. Chemical Composition and Antimicrobial Activity of the Non Volatile Extract and Essential Oils of the Mountain Street (ruta Montana L.). Agronomic Research. 2015;2(27):118-129. 